\title{
Variation in the ability of a long day followed by a short day photoperiod signal to initiate reproductive activity in ewes at different times of the year
}

\author{
T. Sweeney, A. Donovan*, J. F. Roche and D. O'Callaghan ${ }^{\dagger}$ \\ Faculty of Veterinary Medicine, University College Dublin, Ireland
}

\begin{abstract}
Three experiments examined the importance of the time and duration of exposure to a long day followed by a short day photoperiod signal in initiating reproductive activity in ewes. In Expt 1, ewes were maintained on short days ( $8.5 \mathrm{~h}$ light:15.5 h dark) from 21 December interrupted with either 105 long days ( $18 \mathrm{~h}$ light:6 h dark; LD) from 9 February or 35 LD from 9 February, 16 March or 20 April. Exposure to long days followed by short days advanced the onset of reproductive activity in comparison to control ewes maintained on simulated natural photoperiod. Exposure to long days for 105 days delayed the onset of reproductive activity (August $2 \pm 3$ days; $P<0.05$ ) compared with 35 days beginning on the same date (July $13 \pm 5$ days). The interval from the end of the long day signal to the onset of reproductive activity was shorter $(P<0.001)$ however, after $105 \mathrm{LD}$ than after 35 LD. In Expt 2, control ewes were moved from natural photoperiod to simulated natural photoperiod on 1 November and subsequently exposed to short days from 21 December. Four other groups were also exposed to this basic photoperiodic signal sequence but it was interrupted with either $70 \mathrm{LD}$ from 16 November, or $35 \mathrm{LD}$ from 16 November, 21 December or 20 April. More ewes $(P<0.05)$ initiated reproductive activity after exposure to 70 LD from 16 November and 35 LD from 21 December or 20 April compared with control ewes maintained on short days or ewes given 35 LD from 16 November. The interval from the end of long days to the onset of reproductive activity was less $(P<0.01)$ in ewes given 70 LD than in ewes given 35 LD. In Expt 3, ewes on natural photoperiod were given either $90 \mathrm{LD}$ from 21 September, $35 \mathrm{LD}$ from 21 September, 26 October, 30 November, 4 January or 8 February followed by short days. The majority of ewes that received long followed by short days after the winter soistice resumed reproductive activity. However, all photoperiod signals given between the autumn equinox and the winter solstice failed to initiate reproductive activity in ewes during the experiment. Thus we conclude that, in ewes, the reproductive neuroendocrine axis is insensitive to long days followed by short days between the autumn equinox and the winter solstice. The reproductive axis of ewes regains sensitivity to the inductive effects of long days followed by short days at a time close to the winter solstice. Between the winter and summer solstices, long days followed by short days maintain the anoestrous state and provide the cue for initiation of reproductive activity.
\end{abstract}

\section{Introduction}

Under natural photoperiod, ewes begin the breeding season in the autumn (Yeates, 1949; Hafez, 1952), after exposure to a sequence of light signals consisting of increasing daylength before and decreasing daylength after the summer solstice. When sheep are held on a fixed photoperiod, long term changes in reproductive state occur, but the timing of these reproductive transitions is not synchronized between individuals (Ducker et al., 1973; Howles et al., 1982; Almeida and

\footnotetext{
*Present address: Teagasc, Belclare, Tuam, Co. Galway, Ireland.

${ }^{+}$Correspondence.

Received 31 July 1996.
}

Lincoln, 1984; Karsch et al., 1989; Lincoln et al., 1989). This demonstrates that the seasonal reproductive cycle in ewes is generated by an endogenous rhythm and that the expression of this rhythm is entrained to specific times of the year by photoperiod (Karsch et al., 1989; Jansen and Jackson, 1993).

Different phases of the annual photoperiodic cycle provide different cues in entraining the annual reproductive cycle. Exposure to long days is the main photoperiod cue synchronizing the onset of reproductive activity to the autumn in ewes (Malpaux et al., 1989; Wayne et al., 1990) and ewe lambs (Foster et al., 1988a). In fact, the complete annual cycle of changing daylength is not required to initiate seasonal reproductive activity in ewes (Woodfill et al., 1991) or puberty in 
ewe lambs (Foster et al., 1988a, b). Reproductive activity is initiated most effectively by a segment of photoperiodic information similar to that experienced around the summer solstice and least effectively by a segment of photoperiod information similar to that experienced around the winter solstice (Woodfill et al., 1994).

While the critical role of long days followed by short days in initiating reproductive activity has been identified, many of the important characteristics of the long day photoperiod signal have not been characterized. Recent investigations have suggested that there are times of the year when exposure to artificial photoperiod indoors fails to elicit a reproductive response to such a photoperiodic sequence (Khalid and Jackson, 1991; O'Callaghan et al., 1992a). Results from other studies have suggested that long days can have a direct inhibitory effect (Woodfill et al., 1991) and that the duration of exposure to a long day photoperiod signal may be an important component in regulating reproductive activity in ewes (Khalid and Jackson, 1991; Jackson et al., 1988). Therefore, the overall objective of these experiments was to determine whether exposure to different durations of long days followed by short days induces a similar reproductive response in ewes at all times of the year.

The aim of Expt I was to determine whether exposure of ewes to long followed by short days at an earlier time of year than normal advances the onset of reproductive activity in comparison with ewes maintained under simulated natural photoperiod. A second aim was to determine whether it is the initiation of the long day signal or the transfer from long to short days that acts as the main component of the long day signal initiating reproductive activity. The aim of Expt 2 was to determine whether ewes have a different reproductive response to long days followed by short days given before or after the winter solstice. The aim of Expt 3 was to determine whether the onset of reproductive activity can be advanced by exposure to long days followed by short days any time between the autumn equinox and the winter solstice.

\section{Materials and Methods}

\section{Animals and treatments}

Three experiments were carried out using sexually mature Galway ewes during three consecutive years. Ewes were maintained under natural photoperiod at Lyons Research Farm, University College Dublin $\left(53^{\circ} 18^{\prime} \mathrm{N}\right)$ until transferred to photochambers.

Experiment 1: long days in spring. Forty-five cyclic ewes with intact ovaries were placed in photochambers on 21 December (Fig. 1a). Four experimental groups (1a-d) were maintained on short days ( $8.5 \mathrm{~h}$ light:15.5 h dark) from 21 December, interrupted with 105 long days (18 h light: $6 \mathrm{~h}$ dark; LD) from 9 February $(n=9)$ or 35 LD from 9 February $(n=9)$, 16 March $(n=8)$ or 20 April $(n=9)$. A further group of ewes ( $n=10$; control treatment group) was maintained in simulated natural photoperiod (SNP) consisting of a daylength initially equivalent to that of the winter solstice and subsequently adjusted twice weekly to mimic natural changes in photoperiod. Ewes exposed to SNP indicated the onset of the natural breeding season.

Experiment 2: long days around the winter solstice. Fifty-two cyclic ewes with intact ovaries were housed in photochambers on I November on SNP. Control ewes were transferred to short days on 21 December. This basic photoperiod signal sequence was interrupted with long days at different times of the year in different treatment groups (Fig. 1b): 70 LD from 16 November $(n=11)$, or 35 LD from 16 November $(n=11)$, 21 December $(n=10)$ or 20 April $(n=10$; positive control treatment group). A further group of ewes was maintained on continuous short days from 21 December $(n=10$; negative control treatment group). This group indicated the reproductive state of ewes maintained in the absence of a long day photoperiodic signal.

Experiment 3: long days in autumn and winter. Seventy ovariectomized ewes treated with a subcutaneous Silastic capsule (Dow Corp.) containing oestradiol were taken from natural photoperiod and exposed to long days followed by short days (Fig. Ic). The long day treatments were as follows: 90 LD from 21 September $(n=10) ; 35$ LD from 21 September $(n=10), 26$ October $(n=10), 30$ November $(n=10), 4$ January $(n=10)$ and 8 February $(n=10$ positive control treatment group). A further group of ewes ( $n=10$; negative control treatment group) were maintained on short days from 21 December. This group indicated the reproductive state of ewes maintained in the absence of a long day photoperiodic signal.

In all three experiments, photoperiod was regulated by electronic timers operating fluorescent bulbs providing approximately 350 lux lateral to the head of the sheep during periods of illumination. A dim red light producing less than $2 \mathrm{lux}$ at $1 \mathrm{~m}$ from the light source, mounted $2 \mathrm{~m}$ above the sheep remained on continuously to facilitate stock inspection during periods of darkness. The housed animals had access to hay and water ad libitum and received $0.5 \mathrm{~kg}$ per animal per day of supplementary concentrates.

Ewes were maintained in photochambers for 180 days from the end of the long day photoperiod signal or until the onset of reproductive activity, whichever occurred first. As control ewes on short days did not receive a long day photoperiod signal, they were maintained in photoperiod chambers until all other treatments in the experiment were terminated.

\section{Animal models}

Two animal models were used in these experiments. Ovary-intact ewes were used in Expts 1 and 2, in which increased serum concentrations of progesterone indicated the onset of reproductive activity after weekly blood collection. Ovariectomized ewes treated with Silastic capsules containing oestradiol were used in Expt 3, in which serum concentrations of $\mathrm{LH}$ indicated the onset of reproductive activity after weekly blood collection. The similarity of these two models in terms of times of seasonal reproductive transitions has been documented (Legan et al., 1977; Robinson et al., 1985). 

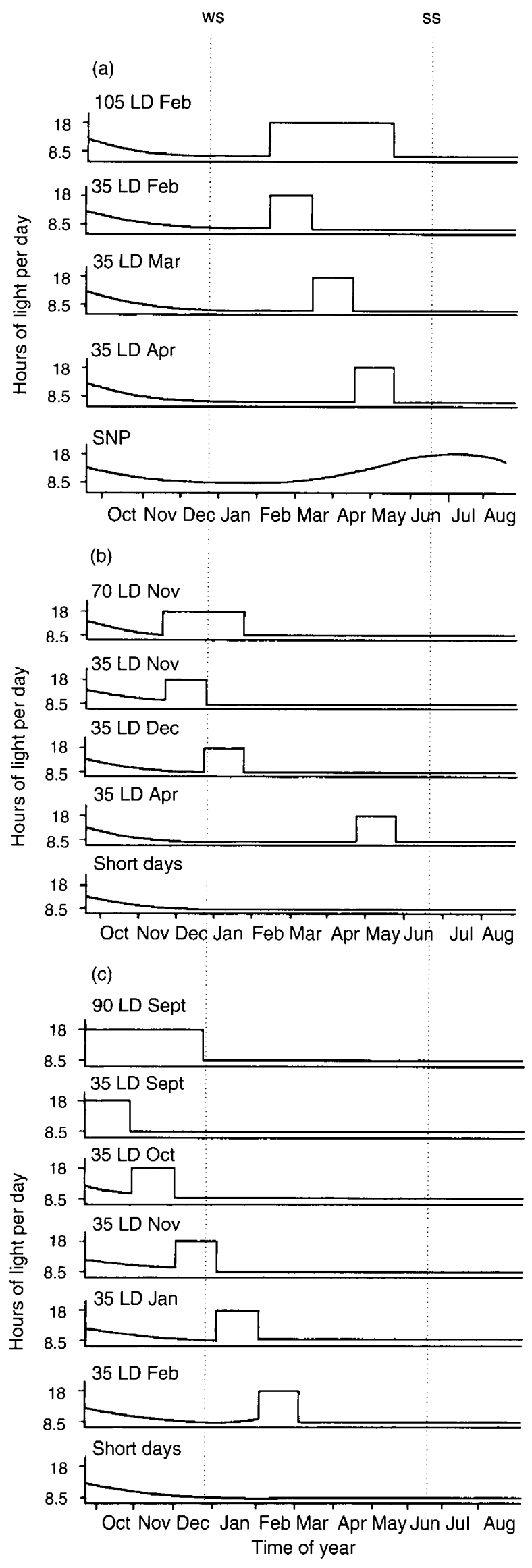

\section{Radioimmunoassays}

Blood samples were stored at room temperature for $1 \mathrm{~h}$ and at $4^{\circ} \mathrm{C}$ for $24 \mathrm{~h}$. Samples were then centrifuged at $700 \mathrm{~g}$ for $20 \mathrm{~min}$. Serum was collected and stored at $-20^{\circ} \mathrm{C}$ until assayed.

Progesterone. Serum progesterone concentrations were determined using the non-extraction radioimmunoassay method of Ronayne and Hynes (1990) modified for serum as described by Donovan et al. (1994). Interassay coefficients of variation $(\mathrm{CV})$ for three serum pools with values of $0.3,1.2$ and $3.2 \mathrm{ng} \mathrm{ml}^{-1}(n=6)$ were $10.9,7.6$ and $7.9 \%$, respectively. Intra-assay $\mathrm{CVs}$ for the same three serum pools were $4.7,4.5$ and $5.1 \%$, respectively. The sensitivity of the assay, as defined by $95 \%$ binding, was $0.05 \mathrm{ng} \mathrm{ml}^{-1}$.

LH. Serum LH concentrations were determined using a modification of the method described by Matteri et al. (1987). Briefly, $200 \mu \mathrm{l}$ aliquots of serum or standard (NIAMDD-oLH24, NIH, USA), $100 \mu \mathrm{l}$ of monoclonal antibody (518B7 antibLH; I:150 000 dilution) and $100 \mu \mathrm{l} \mathrm{I}^{125}$-labelled radioligand (approximately 9000 c.p.m. per tube) were added to tubes on day 1 . Tubes were vortexed and incubated at room temperature for $24 \mathrm{~h}$. On day 2,50 $\mu \mathrm{l}$ donkey antimouse second antibody (SAC-CELL, A-SAC 4, IDS, UK) was added to each tube, vortexed and incubated for $30 \mathrm{~min}$ at room temperature. Distilled water $(250 \mu \mathrm{l})$ was added and tubes were centrifuged at $2500 \mathrm{~g}$ for $20 \mathrm{~min}$. The supernatant was aspirated and the pellet counted for $1 \mathrm{~min}$ in a gamma counter.

Interassay $\mathrm{CVs}$ for three serum pools with values of $0.4,2.1$ and $4.8 \mathrm{ng} \mathrm{ml}^{-1}(n=6)$ were $11.2,6.4$ and $6.5 \%$, respectively. Intra-assay CVs for the same three serum pools were 14.2, 5.9 and $5.8 \%$, respectively. The sensitivity of the assay, defined as $95 \%$ binding, was $0.1 \mathrm{ng} \mathrm{ml}^{-1}$ serum. Crossreactivity of this monoclonal antibody with oFSH at $50 \%$ binding was $7.4 \%$.

\section{Assessment of reproductive state}

Assessment of reproductive state used characteristics of the hormone profile as previously described for this breed

Fig. 1. Photoperiod treatments for ewes in Expts 1-3. (a) Expt 1: long days in spring. Ewes were maintained in photochambers on short days ( $8.5 \mathrm{~h}$ light:15.5 h dark) from 21 December interrupted with 105 long days (LD; $18 \mathrm{~h}$ light:6 h dark) from 9 February, or 35 long days from 9 February, 16 March or 20 April. Control ewes were maintained on simulated natural photoperiod (SNP). (b) Experiment 2: long days around the winter solstice. Ewes were housed in photochambers on I November on SNP. Control ewes were transferred to short days on 21 December. This photoperiod signal sequence was interrupted with long days at different times of the year in different treatment groups: 70 LD from 16 November, or 35 LD from 16 November, 21 December or 20 April. (c) Expt 3: long days in autumn and winter. Ewes were transferred from natural photoperiod to photochambers and given a long day photoperiod treatment followed by short days. The long day treatments were as follows: 90 LD from 21 September; 35 LD from 21 September, 26 October, 30 November, 4 January and 8 February. Control ewes were maintained on short days from 21 December. The winter and summer solstices are indicated by ws and ss, respectively. 
Table 1. The date of onset and interval from start and end of the long day (LD) signal to onset of reproductive activity (RA) in ewes exposed to long days at different times of the year

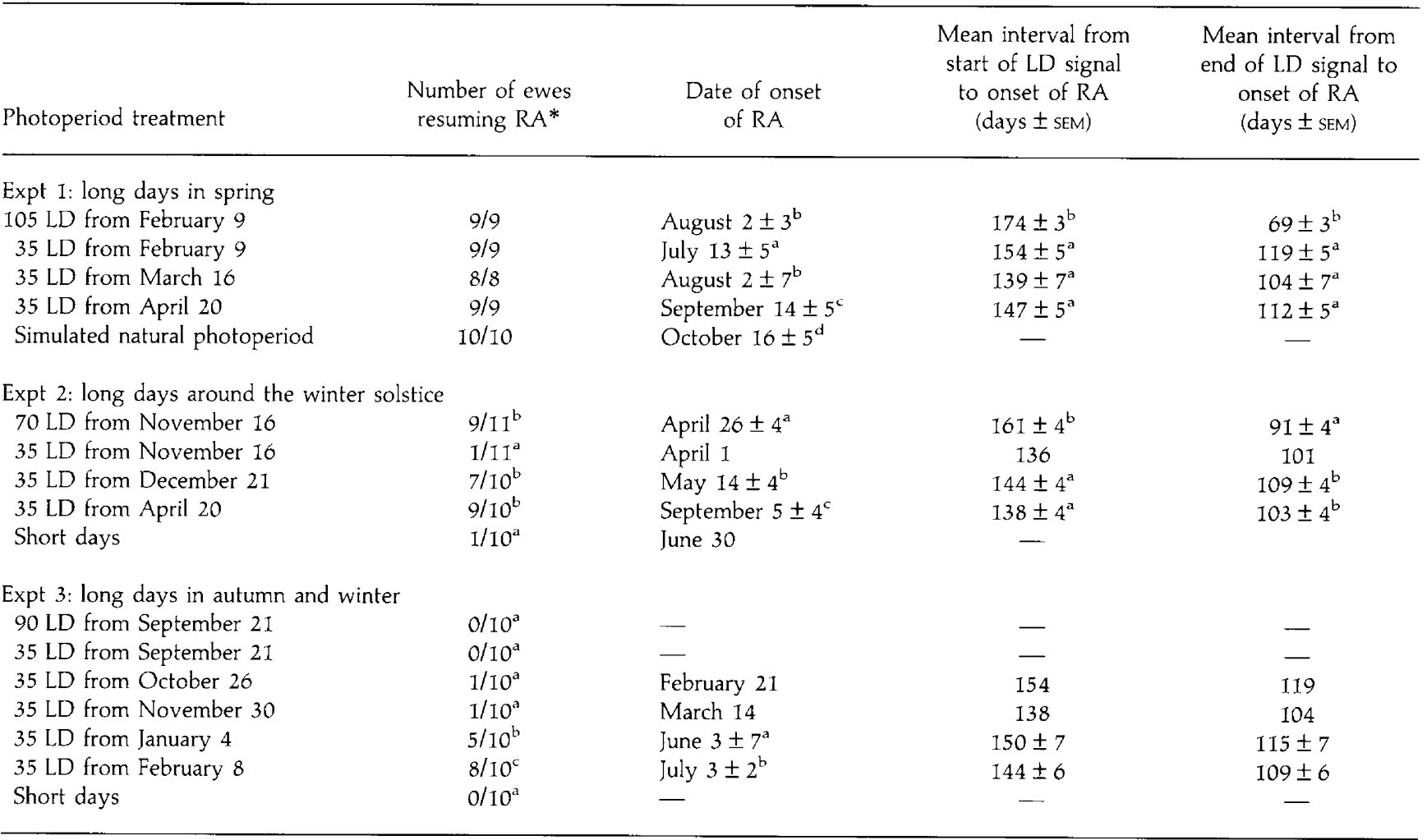

*Number of ewes resuming reproductive activity within 180 days from the day of transfer from long to short days.

Treatment groups with one ewe or fewer resuming reproductive activity were not included in analysis of variance. Statistical comparisons are restricted to within individual experiments. Differences in superscripts indicate significant differences ( ${ }^{\text {abcd }} P<0.05$ ).

(O'Callaghan et al, 1991, 1992b). If ewes had not resumed reproductive activity within 180 days of transfer from long days to short days, it was considered that they had failed to initiate reproductive activity in response to the long day photoperiod signal. In Expts I and 2, the end of reproductive activity was defined as the date of the last serum progesterone value above $0.5 \mathrm{ng} \mathrm{ml}^{-1}$, in a series of two or more points above $0.5 \mathrm{ng} \mathrm{ml}^{-1}$ or one value above $1 \mathrm{ng} \mathrm{ml}^{-1}$, followed in each case by four or more consecutive samples below $0.5 \mathrm{ng}$ $\mathrm{ml}^{-1}$. The onset of reproductive activity was defined as the date of the first serum progesterone value above $0.5 \mathrm{ng} \mathrm{ml}^{-1}$, in a series of two or more points above $0.5 \mathrm{ng} \mathrm{ml}^{-1}$ or one value above $1 \mathrm{ng} \mathrm{ml} \mathrm{ml}^{-1}$ following four or more consecutive samples below $0.5 \mathrm{ng} \mathrm{ml}^{-1}$. In Expt 3, the end of reproductive activity was defined as the date of the first serum LH sample below $1 \mathrm{ng} \mathrm{ml}{ }^{-1}$ in a series of two or more points below $1 \mathrm{ng}$ $\mathrm{ml}^{-1}$. The onset of reproductive activity was defined as the date of the first serum LH sample above $1 \mathrm{ng} \mathrm{ml}^{-1}$, in a series of two or more points above $1 \mathrm{ng} \mathrm{ml}^{-1}$.

\section{Statistical analyses}

As the experiments were carried out in separate years and different animal models were used, the results of each experiment were analysed and presented separately. Differences in the number of ewes per treatment that resumed reproductive activity in response to photoperiodic challenges were analysed using chi-squared analysis. Differences in the time interval from (1) the start of the long day signal and (2) from the end of the long day signal to the onset of reproductive activity were analysed using analysis of variance. Treatment groups in which one or fewer animals initiated reproductive activity in response to photoperiod treatment were not included in this analysis.

\section{Results}

\section{Experiment 1: long days in spring}

All ewes terminated their natural breeding season before exposure to long days commenced and all ewes initiated reproductive activity in response to long days followed by short days. The onset of reproductive activity was advanced $(P<0.05)$ in ewes exposed to a long day followed by a short day photoperiod signal in spring in comparison with ewes exposed to simulated natural photoperiod (Table 1). The time interval from the end of the long day signal to the onset of reproductive activity was decreased $(P<0.001)$ in ewes exposed to 105 compared with 35 long days followed by short days. The time interval from the start of the long day signal to onset of reproductive activity was longer $(P<0.001)$ in ewes exposed to 105 compared with 35 long days followed by short days. 
Experiment 2: long days around the winter solstice

Ewes exposed to long days around the winter solstice (70 LD 16 November, 35 LD 16 November, 35 LD 21 December) followed by short days terminated their natural breeding season earlier $(P<0.002)$ than ewes exposed to continuous short days or $35 \mathrm{LD}$ from April followed by short days. Only one of 10 ewes exposed to short days and one of 11 ewes exposed to 35 LD from 16 November followed by short days resumed reproductive activity during this experiment (Table 1), while a higher proportion $(P<0.05$; at least seven of 10 or 11) resumed reproductive activity after 35 long days given any time after the winter solstice followed by short days. Although most ewes failed to initiate reproductive activity after 35 long days followed by short days from 16 November, nine of 11 ewes exposed to 70 LD from the same date initiated reproductive activity. The time interval from the end of the long day signal to onset of reproductive activity was shorter $(P<0.01)$ in ewes exposed to $70 \mathrm{LD}$ compared with ewes exposed to $35 \mathrm{LD}$ from 21 December and 20 April followed by short days. The time interval from the start of the long day treatment to onset of reproductive activity was not different $(P>0.05)$ in ewes treated with $35 \mathrm{LD}$ from 21 December and 20 April followed by short days. This interval was longer $(P<0.001)$ in ewes given $70 \mathrm{LD}$ followed by short days.

\section{Experiment 3: long days in autumn and winter}

In this experiment, all ewes had increased concentrations of LH from September to January with LH concentrations decreasing at a similar $(P>0.05)$ time, indicating the end of the neuroendocrine breeding season (average of all treatments January $27 \pm 7$ days) regardless of when they were transferred indoors and exposed to a long day signal. More ewes resumed reproductive activity after 35 long days from February followed by short days (eight of 10; Table 1 ) in comparison with 35 long days from January followed by short days (five of 10; $P<0.05$ ), both of which were higher than all other treatments (one ewe or fewer per treatment; $P<0.05$ ). The time intervals from the end of the long day photoperiod signal and the start of the long day signal to the onset of reproductive activity were not different $(P>0.05)$ in treatment groups in which more than one ewe resumed reproductive activity, although a greater number of ewes resumed reproductive activity after exposure to 35 long days from February than from January followed by short days.

\section{Discussion}

The long day component of a photoperiod regimen consisting of long days followed by short days plays a key role in initiating reproductive activity in ewes. These experiments have identified some of the important characteristics of the long day component of this photoperiodic signal. First, these results demonstrate that while ewes initiate reproductive activity in response to 35 long days followed by short days at any stage between the winter and summer solstices, the reproductive neuroendocrine axis is insensitive to a long day signal (35-90 days duration) initiated after the autumn equinox and terminated before the winter solstice followed by continuous exposure to short days. Second, when interpreting the differing time intervals between the beginning and end of the long day signal and onset of reproductive activity, it becomes clear that it is not simply the start or end of the long day signal that times the onset of reproductive activity. While initial exposure to long days is important, exposure to long days for an extended time period (105 days in Expt 1; 70 days in Expt 2) delays the onset of reproductive activity in comparison with ewes exposed to long days for a shorter duration (35 days). After transfer to short days, ewes initiate reproductive activity in a shorter time interval from the end of an extended long day signal (70-105 days) than from the end of a relatively short duration long day photoperiod signal ( 35 days). Thus, between the winter and summer solstices, long days followed by short days maintain the current anoestrous state as well as providing the cue for initiation of reproductive activity.

The time of year that ewes are challenged with long or short day photoperiod signals significantly affects the rate of response to those signals (Jackson et al., 1989). In these experiments, there was a marked difference in the ability of a 35 long day signal followed by continuous exposure to short days administered at different times of the year to influence the reproductive state of ewes. A number of possible explanations can be proposed for the observation that a 35 long day signal at any stage between the autumn equinox and the winter solstice failed to initiate reproductive activity approximately 100 days from transfer to short days. The fact that ewes were reproductively active when treated with long days between the autumn equinox and the winter solstice as they progressed through their natural breeding season could have affected their subsequent reproductive response to long days followed by short days. However, reproductive state does not appear to influence the reproductive response to long days (Woodfill et al., 1992). When pinealectomized ewes in different reproductive states were chalienged with a long day melatonin pattern, ewes that were reproductively active became anoestrous and all ewes resumed reproductive activity within a similar time interval from the end of the long-day signal (Woodfill et al., 1992). In fact, in Expt 2, ewes that were exposed to 35 long days from 21 December were cyclic during exposure to long days and resumed reproductive activity within a similar time interval from the end of the long day signal as anoestrous ewes exposed to 35 long days from April. Similarly, Jackson et al. (1988) reported that a proportion of cyclic ewes exposed to 30 long days in December resumed reproductive activity after transfer to short days. Thus, the current reproductive state does not appear to be a critical factor regulating the ability of ewes to initiate reproductive activity subsequently in response to long days followed by short days.

It is possible that ewes taken from natural photoperiod may be less sensitive to a long-day signal between the autumn equinox and winter solstice and require a signal of a longer duration than 35 days to elicit a subsequent reproductive response. This hypothesis was tested by exposing ewes to a 90 long day signal that spanned this putative insensitive period from the autumn equinox to the winter solstice in Expt 3. This photoperiod signal failed to influence reproductive activity, as 
the ewes terminated their natural breeding season at a similar time to ewes on other treatments and did not initiate reproductive activity within 180 days of the long day signal.

Thus it may be that, in ewes taken from natural photoperiod between the autumn equinox and the winter solstice, the reproductive neuroendocrine axis is refractory to long days. Refractoriness is a condition in which animals become unresponsive to a daylength that previously stimulated or inhibited some physiological function. Between the summer and winter solstice, the photoperiodic history of ewes consists predominantly of increasing daylength before the summer solstice followed by decreasing daylength in the autumn. Thus, it is possible that the neuroendocrine reproductive axis of the ewes is refractory to long days during this period. After the winter solstice, ewes have seen sufficient short days to regain sensitivity to long days. Alternatively, the variation in response to a long day signal at different times of the year could be due to ewes expressing different stages of the endogenous rhythm at the time of the long day signal. The design of these experiments, however, does not differentiate between these two possibilities.

While 35 long days between the autumn equinox and winter solstice followed by continuous exposure to short days failed to induce reproductive activity in ewes, exposure to 35 long days immediately after the winter solstice followed by continuous exposure to short days induced reproductive activity in a proportion of the ewes. In Expt 2, 35 long days from the winter solstice followed by continuous exposure to short days initiated reproductive activity in most ewes, while in Expt 3, 35 LD from January followed by short days initiated reproductive activity in only $50 \%$ of ewes. This varying response to long days around the winter solstice is consistent with previous data (Khalid and Jackson, 1991; O'Callaghan et al., 1992a) and suggests that around this time of year, ewes are demonstrating an increase in sensitivity to long days with a proportion of them becoming reproductively active following transfer from long to short days.

As an increase in sensitivity to a long day signal was observed immediately after the winter solstice, ewes initiated reproductive activity in response to a 35 long day signal followed by short days at any stage between the winter and summer solstice. This supports the hypothesis that at this time of the year, the neuroendocrine reproductive axis is responsive to a long day followed by a short day photoperiodic signal (Malpaux et al., 1989; Wayne et al., 1990; Khalid and Jackson, 1991). This may occur because the endogenous rhythm of reproductive activity is sensitive to long days at this time of year. Alternatively, it may be due to photoperiodic history and the ewes having seen sufficient short days. Evidence from Expt 2, in which ewes failed to elicit a reproductive response to $35 \mathrm{LD}$ in November before the winter solstice, but became reproductively active after exposure to $70 \mathrm{LD}$ from the same date, which spans the winter solstice, provides support for the hypothesis that the endogenous rhythm of reproductive activity is insensitive to a long day photoperiod signal before the winter solstice but becomes sensitive to a long day photoperiod signal after the winter solstice. The data also suggest that there is an interaction between the duration of exposure to long days and the endogenous rhythm of reproductive activity.
In these experiments, the time interval from end of the long day signal to onset of reproductive activity was shorter after exposure to between 70 and 105 long days than it was after exposure to 35 long days. Therefore, it is not simply the start or end of the long day signal that regulates the onset of reproductive activity. As a period of 35 long days is sufficient to initiate reproductive activity, our results support the hypothesis that long days provide a key signal in the photoperiod sequence of long days followed by short days for the initiation of the subsequent breeding season. Prolonged exposure to long days, however, also delays the onset of reproductive activity. This finding suggests that long days have a dual role which includes the initiation of reproductive activity in the long term, but also the inhibition of reproductive activity in the short term. This inhibitory role for long days supports the finding of Wayne et al. (1990) who demonstrated that removal of long days by pinealectomizing ewes on the summer solstice resulted in an earlier onset of reproductive activity. It must be noted that this inhibitory role of long days was not observed by Jackson et al. (1988), who found that the interval from the end of the long day signal was similar after exposure to 30,60 or 90 long days.

In conclusion, the reproductive response of ewes to a long day photoperiodic signal followed by short days depends on the time of year that the signal is given. Ewes are insensitive to a long day signal of up to 90 days given between the autumn equinox and the winter solstice followed by short days, display a varying response to a 35 long day signal followed by short days from the winter solstice, and enter a sensitive phase to the stimulatory effects of long days followed by short days some time after the winter solstice. Our results support the hypothesis that long days have a dual role: after the winter solstice long days provide part of a photoperiod signal required to initiate reproductive activity. Prolonged exposure to long days, however, delays the onset of reproductive activity.

The authors gratefully acknowledge technical assistance from F. Griffith, N. Hynes and the staff of Lyons Research Farm; the Animal Husbandry and Production Research Group at University College Dublin, F. J. Karsch and the members of the Reproductive Sciences Program, The University of Michigan, for help with the experimental designs; J. Roser, University of California, for supplying monoclonal LH antibody; and Clonatec Ltd, Paris, France for supplying monoclonal progesterone antibody.

\section{References}

Almeida OFX and Lincoln GA (1984) Reproductive photorefractoriness in rams and accompanying changes in the patterns of melatonin and prolactin secretion Biology of Reproduction 30 143-158

Donovan A, Boland MP, Roche JF and O'Callaghan D (1994) The effect of supplementary long days, a subcutaneous melatonin implant and exposure to a ram on the onset of the breeding season in ewes Animal Reproduction Science 34 231-240

Ducker MJ, Bowman JC and Temple A (1973) The effect of constant photoperiod on the expression of oestrus in the ewe Journal of Reproduction and Fertility Supplement 19 143-150

Foster DL, Ebling FJP, Claypool LE and Woodfill CJI (1988a) Cessation of long day melatonin rhythms time puberty in a short day breeder Endocrinology 123 1636-1641

Foster DL, Yellon SM, Ebling FJP and Claypool LE (1988bi Are ambient short-day cues necessary for puberty in a short day breeder? Biology of Reproduction 38 821-829 
Hafez ESE (1952) Studies on the breeding season and reproduction of the ewe Journal of Agricultural Science Cambridge 42 189-265

Howles CM, Craigon J and Haynes NB (1982) Long-term rhythms of testicular volume and plasma prolactin concentrations in rams reared for 3 years in constant photoperiod Journal of Reproduction and Fertility 65 439-446

Jackson GL, Gibson M and Kuehl D (1988) Photoperiodic disruption of photorefractoriness in the ewe Biology of Reproduction 38 I27-134

Jackson GL, Jansen HT, Kuehl DE and Shanks RD (1989) Time of sidereal year affects responsiveness to the phase-resetting effects of photoperiod in the ewe Journal of Reproduction and Fertility 85 221-227

Jansen HT and Jackson GL (1993) Circannual rhythms in the ewe: patterns of ovarian cycles and prolactin secretion under two different constant photoperiods Biology of Reproduction 49 627-634

Karsch FJ, Robinson JE, Woodfill CJI and Brown MB (1989) Circannual cycles of luteinizing hormone and prolactin secretion in ewes during prolonged exposure to a fixed photoperiod: evidence for an endogenous reproductive rhythm Biology of Reproduction 41 1034-1046

Khalid M and Jackson GL (1991) Exposure of ewes to long-day photoperiods before the winter solstice can disrupt refractoriness to short days Animal Reproduction Science 25 225-232

Legan SI, Karsch FJ and Foster DL (1977) The endocrine control of seasonal reproductive function in the ewe: a marked seasonal change in response to the negative feedback action of estradiol on luteinizing hormone secretion Endocrinology 101 818-824

Lincoln GA, Libre EA and Merriam GR (1989) Long-term reproductive cycles in rams after pinealectomy or superior cervical ganglionectomy Journal of Reproduction and Fertility $\mathbf{8 5} 687-704$

Malpaux B, Robinson JE, Wayne NL and Karsch FJ (1989) Regulation of the onset of the breeding season of the ewe: importance of long days and of an endogenous reproductive rhythm Journal of Endocrinology $\mathbf{1 2 2}$ 269-278

Matteri RL Roser JF, Baldwin DM, Lipovetsky V and Papkoff H (1987) Characterization of a monoclonal antibody which detects luteinizing hormone from diverse mammalian species Domestic Animal Endocrinology 4 157-165
O'Callaghan D, Karsch FJ, Boland MP and Roche JF (1991) What photoperiodic signal is provided by a continuous-release melatonin implant? Biology of Reproduction 45 927-933

O'Callaghan D, Donovan A, Karsch FJ, Boland MP and Roche JF (1992a) Reproductive response of ewes to a specific photoperiodic challenge at different times of the year. In Proceedings of the Third Meeting of the Society for Research on Biological Rhythms, Jacksonville, FA, Abstract 68

O'Callaghan D, Karsch FJ, Boland MP, Hanrahan, JP and Roche JF (1992b) Variation in the timing of the reproductive season among breeds of sheep in relation to differences in photoperiodic synchronization of an endogenous rhythm Journal of Reproduction and Fertility 96 443-452

Robinson JE, Radford HM and Karsch FJ (1985) Seasonal changes in pulsatile luteinizing hormone $(\mathrm{LH})$ secretion in the ewe: relationship of frequency of LH pulses to daylength and response to estradiol negative feedback Biology of Reproduction 33 324-334

Ronayne E and Hynes N (1990) Measurement of plasma progesterone concentrations by extraction and non-extraction radioimmunoassays Irish Journal of Agricultural Research 29 109-115

Wayne NL, Malpaux B and Karsch FJ (1990) Photoperiodic requirements for timing onset and duration of the breeding season of the ewe: synchronization of an endogenous rhythm of reproduction Journal of Comparative Physiology A 166 835-842

Woodfill CJI, Robinson JE, Malpaux B and Karsch FJ (1991) Synchronization of the circannual reproductive rhythm of the ewe by discrete photoperiodic signals Biology of Reproduction 45 110-121

Woodfill CII, Wayne NL and Karsch FJ (1992) Does seasonal reproductive state affect the neuroendocrine response of the ewe to a long-day pattern of melatonin? Journal of Biological Rhythms 7 1-11

Woodfill CJI, Wayne NL, Moenter SM and Karsch FJ (1994) Photoperiodic synchronization of a circannual reproductive rhythm in sheep: identification of season-specific time cues Biology of Reproduction 50 965-976

Yeates NTM (1949) The breeding season of the sheep with particular reference to its modification by artificial means using light Journal of Agricultural Science Cambridge 39 I-43 